\title{
What does your neighbourhood say about you? A study of life expectancy in 1.3 million Swiss neighbourhoods
}

\author{
André Moser, ${ }^{1,2}$ Radoslaw Panczak, ${ }^{2}$ Marcel Zwahlen, ${ }^{2}$ Kerri M Clough-Gorr, ${ }^{2}$ \\ Adrian Spoerri, ${ }^{2}$ Andreas E Stuck, ${ }^{1}$ Matthias Egger, ${ }^{2,3}$ for the Swiss National Cohort
}

- Additional material is published online only. To view please visit the journal online (http://dx.doi.org/10.1136/jech2014-204352)

${ }^{1}$ Department of Geriatrics, Bern University Hospital and Spital Netz Bern Ziegler and University of Bern, Bern, Switzerland

${ }^{2}$ Institute of Social and Preventive Medicine (ISPM), University of Bern, Bern, Switzerland

${ }^{3}$ School of Social and Community Medicine, University of Bristol, Bristol, UK

\section{Correspondence to} Dr André Moser, Institute of Social and Preventive Medicine (ISPM), University of Bern, Finkenhubelweg 11, Bern CH-3012, Switzerland; amoser@ispm.unibe.ch

Received 3 May 2014 Revised 28 July 2014 Accepted 29 July 2014 Published Online First 14 August 2014
CrossMark

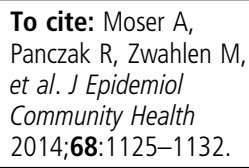

\section{ABSTRACT}

Background Switzerland had the highest life expectancy at 82.8 years among the Organisation for Economic Co-operation and Development (OECD) countries in 2011. Geographical variation of life expectancy and its relation to the socioeconomic position of neighbourhoods are, however, not well understood. Methods We analysed the Swiss National Cohort, which linked the 2000 census with mortality records 2000-2008 to estimate life expectancy across neighbourhoods. A neighbourhood index of socioeconomic position (SEP) based on the median rent, education and occupation of household heads and crowding was calculated for 1.3 million overlapping neighbourhoods of 50 households. We used skewnormal regression models, including the index and additionally marital status, education, nationality, religion and occupation to calculate crude and adjusted estimates of life expectancy at age 30 years.

Results Based on over 4.5 million individuals and over 400000 deaths, estimates of life expectancy at age 30 in neighbourhoods ranged from 46.9 to 54.2 years in men and from 53.5 to 57.2 years in women. The correlation between life expectancy and neighbourhood SEP was strong $(r=0.95$ in men and $r=0.94$ women, both $p$ values $<0.0001$ ). In a comparison of the lowest with the highest percentile of neighbourhood SEP, the crude difference in life expectancy from skew-normal regression was 4.5 years in men and 2.5 years in women. The corresponding adjusted differences were 2.8 and 1.9 years, respectively (all $p$ values $<0.0001$ ). Conclusions Although life expectancy is high in Switzerland, there is substantial geographical variation and life expectancy is strongly associated with the social standing of neighbourhoods.

\section{INTRODUCTION}

Inequalities and inequities in health between and within countries are an important public health concern in many regions, including in high-income countries in Europe and elsewhere. ${ }^{12}$ Members of disadvantaged socioeconomic groups may face barriers to health services; even in countries with universal and public health insurance, they are more likely to be exposed to unemployment or hazardous environments at work and have fewer material and social resources or psychological assets, and less favourable health behaviours. ${ }^{3-5}$ The reduction of inequities in health is therefore a priority on the public health agenda of governments of many countries, including Switzerland. ${ }^{6}$
Life expectancy is a commonly used indicator to measure health inequalities: life expectancy differs widely between countries and states and between regions and neighbourhoods. ${ }^{7-9}$ Regional differences in life expectancy and other health indicators are explained not only by individual and behavioural factors but also by the social and environmental characteristics of communities and neighbourhoods, ${ }^{10}{ }^{11}$ including levels of social capital and cohesion, access to health services, access to green blue spaces and environmental pollutants. Indeed, the place where people live has increasingly become a focus of attention in research on health inequalities. ${ }^{12} 13$

Switzerland had the highest life expectancy at birth at 82.8 years among the Organisation for Economic Co-operation and Development (OECD) countries in $2011,{ }^{14}$ but little is known about differences in life expectancy across communities and neighbourhoods. Previous analyses were based on relatively large administrative areas with arbitrary, fixed boundaries, for example, cantons or urban agglomerations. ${ }^{15}$ While the importance of analyses based on a finer resolution to guide public health policy has been highlighted, ${ }^{11} 1617$ such analyses are lacking for Switzerland and other countries.

We aimed to fill this gap using a recently developed neighbourhood index of socioeconomic position (SEP). ${ }^{18}$ The index is based on census data on household rent, education, occupation and crowding of neighbourhoods of about 50 households. We examined life expectancy across neighbourhoods to jointly explore the spatial epidemiology of health inequalities and social disparities in Switzerland.

\section{METHODS}

\section{Study population}

Described in detail elsewhere ${ }^{19}$ the SNC is a longitudinal study of the entire resident population of Switzerland, based on the 1990 and 2000 national censuses. In brief, deterministic and probabilistic record linkage ${ }^{20}$ was performed using the Generalised Record Linkage System ${ }^{21}$ to link census records to a death record or an emigration record, based on a set of key variables that are available in all data sets (sex, date of birth, place of residence, marital status, religion, nationality, profession and, if applicable, date of birth of partner and date of birth of children). Enumeration in the Swiss census was near-complete: for the 2000 census, coverage is estimated at $98.6 \%{ }^{22}$ Linkage of death and census records is less complete in younger people. We therefore restricted analyses to residents aged 30 years or older. Nursing homes have been shown to distort 
estimates of life expectancy for small areas. ${ }^{23}$ We therefore excluded persons living in nursing homes.

\section{Definition of neighbourhoods and their SEP}

Neighbourhoods of about 50 households were defined. In a first step, each household was spatially referenced using the geographic coordinates of the building. Areas centred on individuals' residences ('ego-centred neighbourhoods') that capture the environmental and social conditions to which an individual is exposed were then created. Boundaries changed from one building to the next and were distorted in the direction of the nearest roads, where shops, amenities and public transportation are typically located. The SEP of neighbourhoods was then determined based on the median rent per square metre, the proportion of households headed by a person with primary education or less, the proportion headed by a person in a manual or unskilled occupation and the mean number of persons per room. The index was standardised to range from 0 (lowest SEP) to 100 (highest SEP). All the data were from the 2000 census. The definition of the overlapping neighbourhoods and the development and validation of the Swiss-SEP is described in detail elsewhere. ${ }^{18}$

\section{Variables}

Individual-level variables included age, sex, education, religion, marital status, nationality and occupation. We classified the highest level of attained education as compulsory schooling or less, secondary, tertiary education or unknown level of education. Religious affiliation was classified into Protestant, Roman Catholic, no religious affiliation or other religious affiliation. Marital status was defined as single, married, divorced or widowed and nationality as Swiss, European or other. As in a previous study, ${ }^{24}$ we collapsed the 33 grade socioprofessional categorisation of occupations developed by the Swiss Federal Statistical Office into eight categories of socioprofessional status capturing the skill level and position of individuals on the labour market: top management and independent professions, other self-employed professions, professionals and senior management, supervisors, lower management and skilled labour, unskilled employees and workers, people in paid employment (not classified elsewhere), unemployed or job-seeking, and persons not in paid employment.

\section{Statistical methods}

Life expectancy at age 30 was estimated using a skew-normal regression approach accounting for left-truncated and rightcensored observations. ${ }^{25}$ Parameter estimates from the models are directly interpretable as differences of life expectancy. We used life years, measured from age 30 to age at 31 December 2008 or death, as the dependent variable with a delayed entry date of 5 December 2000 (the day of the 2000 census). As life expectancy is higher in women than in men and associations of covariates with life expectancy may also differ between genders, we performed analyses separately for women and men. Crude estimates included one variable at a time, for example, the index of neighbourhood SEP. The index of neighbourhood SEP was modelled as a restricted cubic spline with five knots. ${ }^{26}$ Differences of life expectancy are reported across the full range of the distribution of the index, at the 1th, 10th, 25th, 50th, 75th, 90th and 99th percentile. We used the median $(50 \%)$ as the reference when comparing percentiles. Adjusted models additionally included all individual-level variables, that is, age, sex, education, religion, marital status, nationality and occupation. We averaged life expectancy estimates across neighbourhoods by a simple moving average approach and assessed correlations between life expectancy and the SEP of neighbourhoods using Pearson's correlation coefficients.

Results are presented as maps, with colour-coded dots representing buildings and the estimated life expectancy of their neighbourhood, and as crude and adjusted differences in life expectancy. Statistical analyses were performed in Stata V.12.1 (Stata Corporation, College Station, Texas, USA) and R V.3.0.2 (R Project, University of Vienna, Austria).

\section{RESULTS}

\section{Characteristics of study population}

The analysis was based on 4526759 individuals aged 30 years or older at the 2000 census who lived in 1298079 million neighbourhoods and 3092714 million geo-referenced households. A total of 414676 individuals died between 5 December 2000 and 31 December 2008 and were linked to a census record. Among these deaths, 25648 (6.2\%) could not be linked probabilistically but were pragmatically assigned a census record, based on age and sex, as described elsewhere. ${ }^{27}$ The median age at the 2000 census was 51.2 years among women and 49.3 years among men (table 1). Women were more often widowed (12.8\% compared to $2.8 \%$ in men) and less educated than men $(31.0 \%$ of women had compulsory education or less compared to $16.5 \%$ among men). In women and men, the dominant religious affiliations were the Protestant and Roman Catholic faiths; $10.1 \%$ of women and $13.2 \%$ of men reported no religious affiliation. There were fewer women in the higher socioprofessional categories than men and more women than men were not in paid employment $(46.6 \%$ compared to $24.2 \%$ in men). The crude estimates of life expectancy at age 30 years were 49.8 years in men and 54.6 years in women, close to the life expectancies reported by the Federal Office of Statistics for the study period (49.7 years in men and 54.3 years in women). There were few individuals with missing data $(2.5 \%$ missing for education, $3.5 \%$ missing for religion) and results were similar when excluding them.

\section{Geographical patterns of life expectancy at age 30 years}

Maps of estimated life expectancy at age 30 years in men and women are shown in figure 1. Across the 1.3 million neighbourhoods, estimated life expectancy at age 30 years ranged from 46.9 to 54.2 years in men and from 53.5 to 57.2 years in women. Neighbourhoods of higher life expectancy (in shades of yellow) are concentrated in the urban centres, most notably in Zurich, Geneva, Basel, Lausanne, Bern and surroundings; and along some of the lakes, for example, the arc of Lake Geneva and both sides of Lake Zurich. Neighbourhoods of lower life expectancy (in shades of purple) dominate regions immediately north of the Alps, the area north of the lakes of Neuchâtel and Bienne in the West of the country and much of the valleys of the Alps. Within the major cities, differences were evident at the level of streets (see online supplementary figures S1-S5).

\section{Determinants of life expectancy}

There were substantial differences across neighbourhoods of different SEP in crude models: in men, comparing the 1 th with the 99th percentile of neighbourhood SEP, the difference was 4.5 years of additional life expectancy and it was 2.5 years in women. Substantial differences were also observed by marital status, level of education, nationality and across occupational categories (table 2). For example, comparing the unemployed to those working in top management positions or in independent professions, the difference in life expectancy was 13.0 years in 
Table 1 Characteristics of the male and female study population in 2000

\begin{tabular}{|c|c|c|}
\hline & $\begin{array}{l}\text { Men } \\
\text { N (\%) }\end{array}$ & $\begin{array}{l}\text { Women } \\
\mathrm{N}(\%)\end{array}$ \\
\hline \multicolumn{3}{|l|}{ Age at census } \\
\hline $30-<40$ & $594152(27.3)$ & $595037(25.3)$ \\
\hline $40-<50$ & $527648(24.2)$ & $520663(22.2)$ \\
\hline $50-<60$ & $460777(21.2)$ & 460948 (19.6) \\
\hline $60-<70$ & $308199(14.2)$ & 343514 (14.6) \\
\hline $70-<80$ & $203007(9.3)$ & $281358(12.0)$ \\
\hline$\geq 80$ & $83244(3.8)$ & $148212(6.3)$ \\
\hline \multicolumn{3}{|l|}{ Marital status } \\
\hline Single & $347546(16.0)$ & $290071(12.3)$ \\
\hline Married & 1608157 (73.9) & $1530874(65.2)$ \\
\hline Widowed & 61766 (2.8) & 301909 (12.8) \\
\hline Divorced & $159558(7.3)$ & $226878(9.7)$ \\
\hline \multicolumn{3}{|l|}{ Education } \\
\hline Compulsory or less & $358460(16.5)$ & 727839 (31.0) \\
\hline Secondary & $1087642(50.0)$ & $1243527(52.9)$ \\
\hline Tertiary & 681003 (31.3) & 322213 (13.7) \\
\hline Unknown & $49922(2.3)$ & $56153(2.4)$ \\
\hline \multicolumn{3}{|l|}{ Nationality } \\
\hline Swiss & 1729979 (79.5) & 1986181 (84.5) \\
\hline European Union & 401920 (18.5) & 321280 (13.7) \\
\hline Other & $45128(2.1)$ & $42271(1.8)$ \\
\hline \multicolumn{3}{|l|}{ Religion } \\
\hline Protestant & 769958 (35.4) & 906752 (38.6) \\
\hline Roman Catholic & 909435 (41.8) & $1004079(42.7)$ \\
\hline No religious affiliation & $287323(13.2)$ & 237943 (10.1) \\
\hline Other/unknown & $210311(9.7)$ & 200958 (8.6) \\
\hline \multicolumn{3}{|l|}{ Occupation } \\
\hline Top management, independent professions & $86510(4.0)$ & $23254(1.0)$ \\
\hline Other self-employed & $219291(10.1)$ & $87522(3.7)$ \\
\hline Professionals/senior management & $200942(9.2)$ & $67631(2.9)$ \\
\hline Lower management and skilled labour & 643369 (29.6) & $534980(22.8)$ \\
\hline Unskilled employees and workers & $130188(6.0)$ & $163449(7.0)$ \\
\hline Paid employment, not classified & $326132(15.0)$ & $318280(13.6)$ \\
\hline Unemployed & $43459(2.0)$ & $58932(2.5)$ \\
\hline Not in paid employment & $527136(24.2)$ & 1095684 (46.6) \\
\hline
\end{tabular}

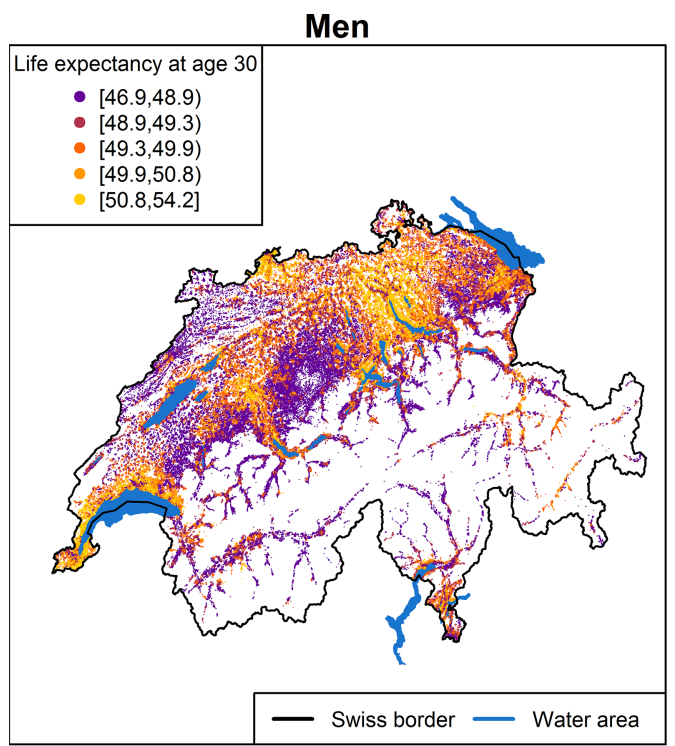

men and 5.7 years in women. The difference between single men and married men was 5.4 years, and between single women and married women it was 4.0 years. Estimates for residents with a nationality other than Swiss were higher, with larger differences observed in men than in women, probably reflecting the healthy migrant effect and under ascertainment of deaths in migrants returning home due to sickness. Some differences in life expectancy were also noted across religious affiliations, with Catholics living somewhat longer than Protestants (table 2).

In adjusted models, differences across neighbourhood SEP were attenuated but substantial differentials remained: 2.8 years in men and 1.9 years in women. Estimates of differences also changed for some individual-level variables. For example, differences between educational levels became smaller and differences across nationalities larger (table 2). The crude and adjusted differences across percentiles of the Swiss-SEP index were reduced when moving from age 30 to higher ages; however, even at age 80 , substantial differences were evident both in the unadjusted and fully adjusted analyses (figure 2).

\section{Correlation between life expectancy and neighbourhood SEP}

There was a strong correlation between life expectancy and neighbourhood SEP: $r=0.95$ and 0.94 , respectively, in men and women ( $\mathrm{p}<0.0001$ for both coefficients). The scatter plots of life expectancy against the index of neighbourhood SEP suggested that there were two slopes: a flatter one for neighbourhoods of lower SEP and a steeper one for neighbourhoods of higher SEP. This was confirmed in the analysis based on restricted cubic splines, which showed that the increase in life expectancy was steeper from the 50th percentile of the neighbourhood SEP onwards, and that it was steeper in men than in women (figure 3).

\section{DISCUSSION}

We created a detailed map of life expectancy at age 30 years for 1.3 million Swiss neighbourhoods and examined the determinants of life expectancy. We found that estimated life expectancy varied substantially between neighbourhoods, and between neighbourhoods of different SEP, with differences of about 4.5 years in men and 2.5 years in women between the 1 th and 99th percentile of neighbourhood SEP, and a strong correlation

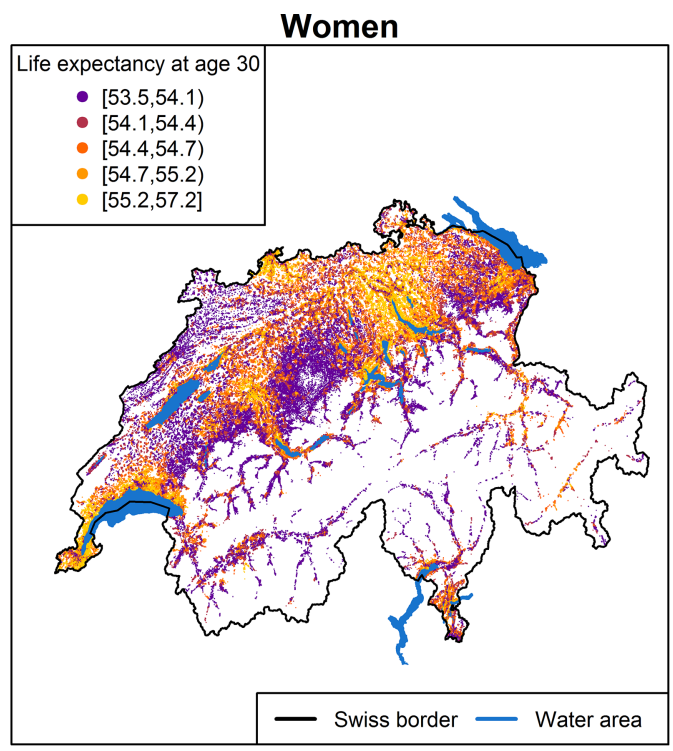

Figure 1 Maps of estimated life expectancy at age 30 in Switzerland by gender. 
Table 2 Differences in life expectancy by neighbourhood and sociodemographic characteristics for male and female Swiss residents, 20002008

\begin{tabular}{|c|c|c|c|c|c|c|c|c|}
\hline & \multicolumn{4}{|l|}{ Men } & \multicolumn{4}{|c|}{ Women } \\
\hline & \multicolumn{2}{|c|}{ Crude } & \multicolumn{2}{|c|}{ Adjusted } & \multicolumn{2}{|c|}{ Crude } & \multicolumn{2}{|c|}{ Adjusted } \\
\hline & DLE & $(95 \% \mathrm{Cl})$ & DLE & $(95 \% \mathrm{Cl})$ & DLE & $(95 \% \mathrm{Cl})$ & DLE & $(95 \% \mathrm{Cl})$ \\
\hline \multicolumn{9}{|l|}{ Index of neighbourhood SEP } \\
\hline 1th percentile & -1.4 & $(-1.6$ to -1.2$)$ & -0.9 & $(-1.2$ to -0.7$)$ & -0.7 & $(-0.9$ to -0.5$)$ & -0.6 & $(-0.8$ to -0.4$)$ \\
\hline 10th percentile & -0.9 & $(-1.0$ to -0.7$)$ & -0.5 & $(-0.6$ to -0.4$)$ & -0.5 & $(-0.6$ to -0.4$)$ & -0.4 & $(-0.6$ to -0.3$)$ \\
\hline 25th percentile & -0.6 & $(-0.7$ to -0.4$)$ & -0.3 & $(-0.4$ to -0.2$)$ & -0.4 & $(-0.5$ to -0.3$)$ & -0.3 & $(-0.4$ to -0.2$)$ \\
\hline 50th percentile & 0 & & 0 & & 0 & & 0 & \\
\hline 75th percentile & 1.1 & (0.9 to 1.2$)$ & 0.7 & (0.6 to 0.8$)$ & 0.6 & (0.4 to 0.7$)$ & 0.4 & (0.3 to 0.5$)$ \\
\hline 90th percentile & 1.9 & (1.8 to 2.1$)$ & 1.2 & (1.1 to 1.4$)$ & 1.1 & (0.9 to 1.2$)$ & 0.8 & (0.7 to 0.9$)$ \\
\hline 99th percentile & 3.1 & (2.9 to 3.4$)$ & 1.9 & (1.6 to 2.1$)$ & 1.8 & (1.6 to 2.0$)$ & 1.3 & (1.1 to 1.6$)$ \\
\hline \multicolumn{9}{|l|}{ Marital status } \\
\hline Single & -5.4 & $(-5.5$ to -5.2$)$ & -4.9 & $(-5.1$ to -4.8$)$ & -4.0 & $(-4.2$ to -3.9$)$ & -4.6 & $(-4.8$ to -4.5$)$ \\
\hline Married & 0 & & 0 & & 0 & & 0 & \\
\hline Widowed & -2.4 & $(-2.5$ to -2.2$)$ & -2.1 & $(-2.3$ to -2.0$)$ & -4.0 & $(-4.1$ to -3.8$)$ & -4.1 & $(-4.2$ to -4.0$)$ \\
\hline Divorced & -3.5 & $(-3.7$ to -3.4$)$ & -3.8 & $(-4.0$ to -3.6$)$ & -3.4 & $(-3.6$ to -3.3$)$ & -3.9 & $(-4.0$ to -3.7$)$ \\
\hline \multicolumn{9}{|l|}{ Education } \\
\hline Compulsory or less & -4.2 & $(-4.3$ to -4.1$)$ & -2.9 & $(-3.1$ to -2.7$)$ & -2.0 & $(-2.2$ to -1.9$)$ & -1.8 & $(-2.0$ to -1.6$)$ \\
\hline Secondary & -2.8 & $(-2.9$ to -2.7$)$ & -1.9 & $(-2.0$ to -1.8$)$ & -1.0 & $(-1.1$ to -0.8$)$ & -0.9 & $(-1.1$ to -0.7$)$ \\
\hline Tertiary & 0 & & 0 & & 0 & & 0 & \\
\hline Not known & -3.8 & $(-4.1$ to -3.4$)$ & -1.8 & $(-2.2$ to -1.4$)$ & -1.9 & $(-2.2$ to -1.6$)$ & -1.3 & $(-1.6$ to -0.9$)$ \\
\hline \multicolumn{9}{|l|}{ Nationality } \\
\hline Swiss & 0 & & 0 & & 0 & & 0 & \\
\hline European Union & 2.1 & (1.9 to 2.2 ) & 3.0 & (2.8 to 3.1$)$ & 1.5 & (1.3 to 1.7$)$ & 1.9 & (1.7 to 2.1 ) \\
\hline Other & 3.8 & (3.3 to 4.3 ) & 5.0 & (4.4 to 5.7 ) & 1.5 & (0.9 to 2.1 ) & 2.3 & (1.6 to 2.9 ) \\
\hline \multicolumn{9}{|l|}{ Religion } \\
\hline Protestant & -0.1 & $(-0.2$ to 0.0$)$ & -0.3 & $(-0.4$ to -0.2$)$ & -0.3 & $(-0.4$ to -0.2$)$ & -0.5 & $(-0.6$ to -0.4$)$ \\
\hline Roman Catholic & 0 & & 0 & & 0 & & 0 & \\
\hline No affiliation & 0.4 & (0.3 to 0.6$)$ & 0.0 & $(-0.2$ to 0.2$)$ & -0.1 & $(-0.3$ to 0.1$)$ & -0.5 & $(-0.7$ to -0.3$)$ \\
\hline Other/unknown & -0.4 & $(-0.6$ to -0.3$)$ & -0.5 & $(-0.7$ to -0.3$)$ & -0.6 & $(-0.7$ to -0.4$)$ & -0.9 & $(-1.0$ to -0.7$)$ \\
\hline \multicolumn{9}{|l|}{ Occupation } \\
\hline Top management, independent professions & 3.7 & (3.2 to 4.2 ) & 1.9 & (1.4 to 2.4$)$ & 0.7 & $(-0.2$ to 1.6$)$ & 0.0 & $(-0.9$ to 1.0$)$ \\
\hline Other self-employed & -0.2 & $(-0.6$ to 0.1$)$ & -0.3 & $(-0.6$ to 0.0$)$ & 0.3 & $(-0.1$ to 0.8$)$ & -0.1 & $(-0.6$ to 0.4$)$ \\
\hline Professionals, senior management & 4.1 & (3.7 to 4.5 ) & 2.3 & (1.9 to 2.7$)$ & 0.6 & (0.0 to 1.2$)$ & 0.1 & $(-0.6$ to 0.7$)$ \\
\hline Lower management, skilled labour & 0 & & 0 & & 0 & & 0 & \\
\hline Unskilled employees, workers & -1.8 & $(-2.1$ to -1.4$)$ & -1.4 & $(-1.8$ to -1.0$)$ & 0.1 & $(-0.3$ to 0.4$)$ & 0.4 & (0.0 to 0.8$)$ \\
\hline Paid employment, not classified & -3.5 & $(-3.8$ to -3.3$)$ & -3.3 & $(-3.6$ to -3.0$)$ & -0.9 & $(-1.2$ to -0.7$)$ & -1.4 & $(-1.7$ to -1.1$)$ \\
\hline Unemployed & -9.3 & $(-9.8$ to -8.8$)$ & -8.6 & $(-9.0$ to -8.1$)$ & -5.0 & $(-5.4$ to -4.5$)$ & -5.5 & $(-6.0$ to -5.0$)$ \\
\hline Not in paid employment & -8.3 & $(-8.6$ to -8.1$)$ & -7.3 & $(-7.6$ to -7.0$)$ & -2.0 & $(-2.2$ to -1.8$)$ & -2.9 & $(-3.1$ to -2.6$)$ \\
\hline
\end{tabular}

DLE, differences in life expectancy (years); SEP, socioeconomic position.

between life expectancy and SEP. At the individual level, marital status, education, occupation and nationality were also strongly associated with life expectancy.

The neighbourhood index of SEP was constructed using individual-level information on education and occupation and household-level information on rent and crowding. The definition of the boundaries of neighbourhoods took into account access to amenities and public transportation in the vicinity. ${ }^{18} \mathrm{It}$ is therefore likely that the neighbourhoods and their index of SEP also capture contextual neighbourhood effects, rather than mainly compositional effects that stem from the population characteristics of residents in the neighbourhoods. Indeed, when we adjusted for the two compositional variables included in the index (education and occupation), and other variables associated with life expectancy, an important association remained with neighbourhood.

Other strengths of this study include its national coverage and the fact that the outcome of interest, life expectancy, was based on routine mortality statistics. 'Same-source bias', when relationships emerge due to the fact that the data were collected from the same single source, can thus be excluded. ${ }^{28}$ Neighbourhoods were of uniformly small size. Previous studies were often based on larger census or electoral wards of varying size, or even towns, driven by the availability of geographically defined data. ${ }^{15}$ Such analyses suffer from what geographers describe as the 'modifiable areal unit problem', where different levels of aggregation of the data yield different and potentially misleading results. ${ }^{18} 29$ The problem is related to ecological bias and the ecological fallacy in epidemiology, when misleading relationships between variables are deduced from the correlation of these variables at the aggregated level, for example, geographical areas. ${ }^{30}$

We examined life expectancy at age 30 years, but differences in life expectancy across neighbourhoods of different SEP will be larger and relative gradients might be steeper at birth: life expectancy at birth is particularly responsive to differences in 
Figure 2 Additional years in life expectancy at ages 30 to 80 by percentiles of Swiss-socioeconomic position (SEP) and gender.

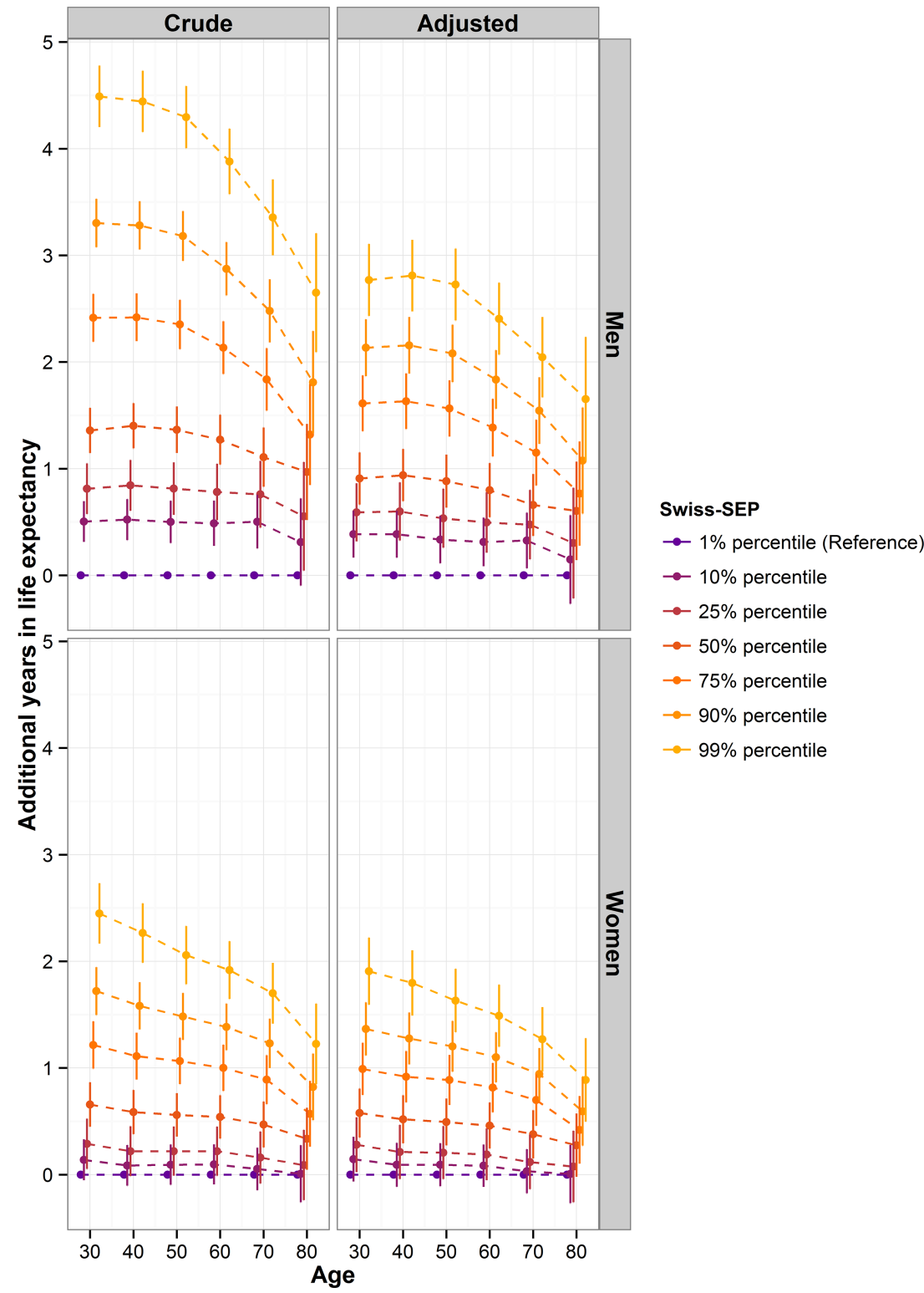

mortality rates at a young age and these were not captured by our analysis. ${ }^{31}$ In England and Wales, a study of geographical variation in life expectancy at birth using the income domain score of the Index of Multiple Deprivation (IMD 2000) found that men living in the most affluent fifth of wards had almost five additional years of life expectancy at birth compared with those living in the most deprived fifth. ${ }^{32}$ For women, the corresponding figure was 3.6 years.

The differentials in life expectancy observed in this study are nevertheless substantial. According to the estimates of the Global Burden of Disease (GBD) Study 2010, ${ }^{7}$ these differences are larger than the increase in life expectancy at age 30-34 years observed in Switzerland between 2000 and 2010 (2.4 years in men and 1.5 years in women), and are in the same order of magnitude as the differences in life expectancy 2010 at age 30-34 years observed between Switzerland and some middle-income countries, for example, Cuba, Ecuador or Taiwan. ${ }^{7}$ Switzerland ranks highly in the GBD study's country list for healthy life expectancy at birth: third for men and fifth for women in 2010. ${ }^{7}$ Although we did not assess healthy life expectancy at birth, it seems likely that life expectancy experienced by those in the highest percentile of SEP would move Switzerland to the top, whereas that experienced in the lowest percentile of neighbourhood SEP would move it into the group of middle-income countries.

There are several factors through which neighbourhoods may affect the health of their residents. Physical and environmental exposures that differ between areas include altitude, air pollution, noise and ionising and non-ionising radiation. For example, a recent analysis of the European Study of Cohorts for Air Pollution Effects found that long-term exposure to fine particulate air pollution was associated with mortality from natural causes, even within concentrations below the limits mandated by European air quality standards. ${ }^{33}$ Previous analyses of the Swiss National Cohort showed that living at higher altitudes was associated with lower coronary heart disease and stroke mortality ${ }^{34}$ and that exposure to high levels of aircraft noise was associated with death from acute myocardial infarction, whereas mortality from lung cancer increased with higher levels of air pollution. ${ }^{35}$ Furthermore, exposure to green spaces such as parks, forests and river corridors has been shown to have beneficial effects on psychological well-being, ${ }^{36}$ to stimulate recovery from surgery ${ }^{37}$ and to be associated with reduced mortality. ${ }^{38}$ 
Figure 3 Difference in life expectancy at age 30 across levels of neighbourhood socioeconomic position. Median Swiss-socioeconomic position (SEP) is the reference.

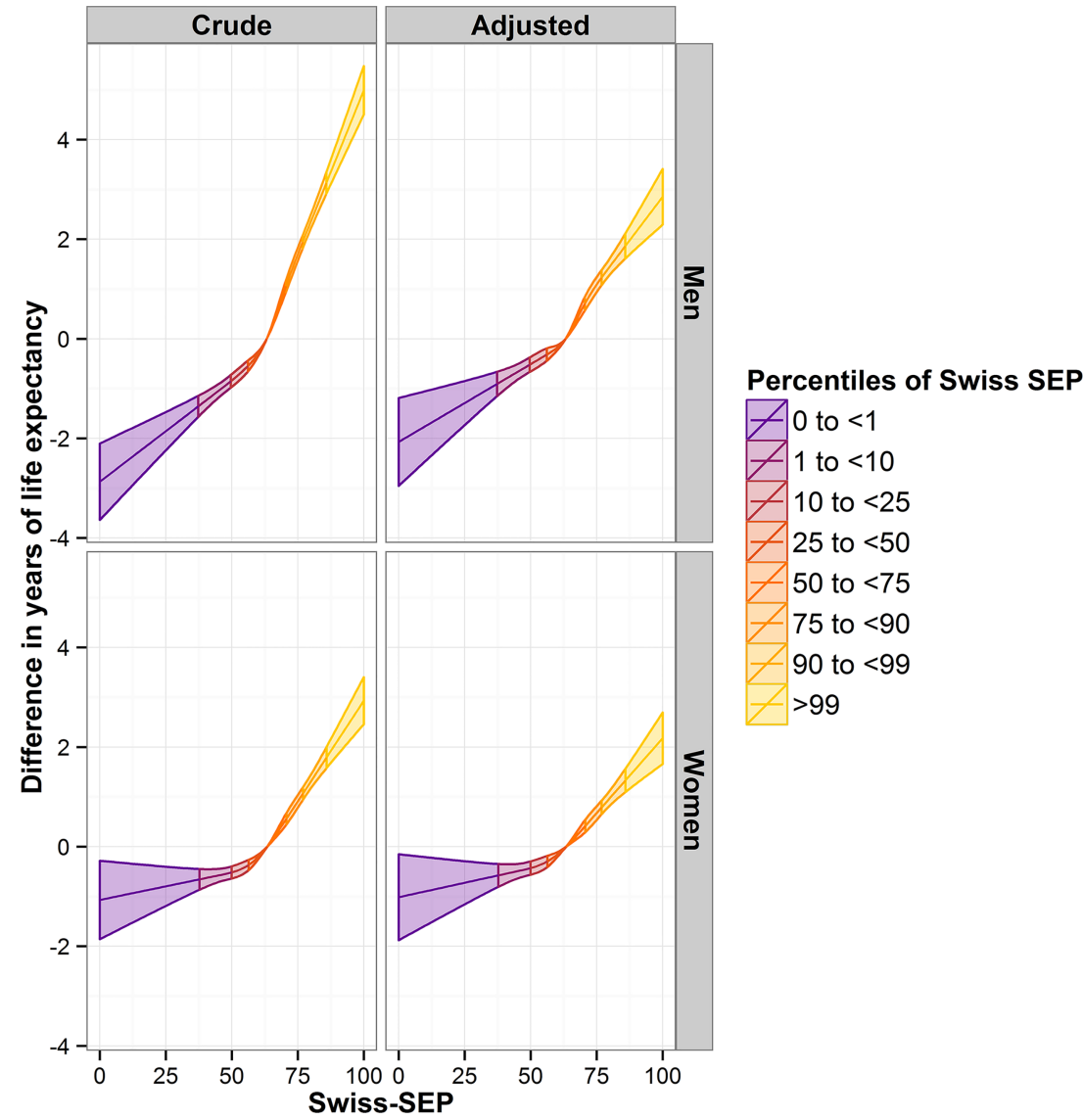

Few studies explicitly examined associations between neighbourhood SEP and environmental and lifestyle exposures. The longitudinal Multi-Ethnic Study of Atherosclerosis in the USA found that higher levels of air pollutants were associated with lower individual and neighbourhood SEP. ${ }^{39}$ Similarly, a study in London, UK, found that mean air pollution was greater for areas and individuals with lower SEP. ${ }^{40}$ However, results were not uniform across London, with associations in the opposite direction in affluent central areas exposed to high levels of air pollution. ${ }^{40} \mathrm{~A}$ small-area analysis of residential exposure to road traffic noise and social deprivation in Marseilles, France, found that the association was not linear, with the highest noise exposure in midlevel deprivation areas. ${ }^{41}$ In Australia's major cities, access to green space was substantially lower in neighbourhoods with a higher percentage of residents with low incomes. The strength of the association between green space and neighbourhood SEP varied, with steeper gradients in Sydney and Adelaide, and a flatter gradient in Melbourne. ${ }^{42}$ In a study in Kiel in Northern Germany, variation in childhood overweight was partly explained by the SEP of neighbourhoods. ${ }^{43}$ In the Portland cohort of the Study for Osteoporotic Fractures in Women, higher neighbourhood SEP was associated with a healthier body mass index at baseline, and a less pronounced age-related decline in body mass index over time. ${ }^{44}$

The social environment and, in particular, different levels of social cohesion or social capital may also influence health and mortality. ${ }^{45}$ Interestingly, the Catholic faith was associated with a slightly higher life expectancy than the Protestant faith. On the basis of a comparison of Catholic and Protestant cantons in Switzerland and other data, the French sociologist Emile Durkheim argued in 1897 that stronger social cohesion and social integration among Catholics resulted in lower suicide rates in their communities. ${ }^{46}$ Catholics are required to interact with others frequently when going to mass, obtaining sacraments and confessing, and may therefore benefit from supportive social networks. The differences in rates of suicide between Catholics and Protestants continue in Switzerland to the present day $^{47}$ and may have contributed to the differences in life expectancy observed here.

Differential access to healthcare may contribute to inequities in health, but this is unlikely to be a major factor in Switzerland. Switzerland has a well-developed health system and universally mandated health insurance, which guarantees access. A study of regional differences in the use of care found that such differences probably reflect the inappropriate use of specialist care, rather than differential access to care in general. ${ }^{48}$ Finally, neighbourhoods may influence health through behavioural pathways, for example, by discouraging smoking, or offering opportunities for physical activities. Unfortunately, we were unable to examine the importance of different mechanisms and pathways due to the lack of data on, for example, the social cohesion of neighbourhoods or the health behaviours of their residents.

The association of life expectancy with the SEP of neighbourhoods, and other variables such as educational attainment, indicate that the differentials observed in this study can be reduced by policies aiming to improve the physical and social environment people live in, and health promotion targeting individual behaviours. The high-resolution maps presented here should help in the planning of such interventions and setting of priorities. Absolute differences in life expectancy at birth between cantons are substantially smaller in Switzerland today than at the beginning of the 20th century, when men from the Canton of Geneva lived more than 10 years longer than their 
counterparts in the Canton of Ticino. ${ }^{15}$ However, our study shows that substantial inequalities persist between small areas. Future research should examine what causes of death mainly generate these disparities, and to what extent they have been reduced relative to the trends in underlying rates of mortality.

\section{What is already known about this subject}

- Regional differences in life expectancy are explained not only by individual and behavioural factors but also by the social and environmental characteristics of neighbourhoods.

- Switzerland has one of the highest life expectancies in the world, but little is known about the differences in life expectancy across communities and neighbourhoods.

- The Swiss index of neighbourhood socioeconomic position is based on census data on household rent, education, occupation and crowding.

\section{What this study adds}

- Shown on a map for 1.3 million Swiss neighbourhoods, life expectancy at age 30 years ranged from 46.9 to 54.2 years in men and from 53.5 to 57.2 years in women.

- There was a strong correlation between life expectancy and neighbourhood socioeconomic position (SEP), and large differences in life expectancy were evident across levels of neighbourhood SEP.

- When adjusting for characteristics of individuals (age, sex, education, religion, marital status, nationality and occupation), differences across neighbourhood SEP were attenuated but substantial differentials remained.

Collaborators The members of the Swiss National Cohort Study Group are Matthias Egger (Chairman of the Executive Board), Adrian Spoerri and Marcel Zwahlen (Bern, Switzerland); Milo Puhan (Chairman of the Scientific Board), Matthias Bopp and David Faeh (Zurich, Switzerland); Nino Kuenzli (Basel, Switzerland); Fred Paccaud (Lausanne, Switzerland); and Michel Oris (Geneva, Switzerland). The authors thank the Swiss Federal Statistical Office, whose support made the Swiss National Cohort possible.

Contributors ME developed the original idea for the study. AM and RP designed and implemented the data processing and analysis. MZ supervised the statistical analysis. AM and ME wrote the first draft of the paper. All authors have read and approved the final manuscript as well as contributed to the writing and the methodology used in the study.

Funding This work was supported by the Swiss National Science Foundation (SNSF), grant number 33CS30-134273.

Competing interests None.

Ethics approval Ethics approval was provided by Cantonal Ethics Committee Bern. Provenance and peer review Not commissioned; externally peer reviewed.

\section{REFERENCES}

1 Lozano R, Naghavi M, Foreman K, et al. Global and regional mortality from 235 causes of death for 20 age groups in 1990 and 2010: a systematic analysis for the Global Burden of Disease Study 2010. Lancet 2012;380:2095-128.

2 Mackenbach JP, Stirbu I, Roskam AJ, et al. Socioeconomic inequalities in health in 22 European countries. N Engl J Med 2008;358:2468-81.

3 Marmot M, Friel S, Bell R, et al. Commission on Social Determinants of Health. Closing the gap in a generation: health equity through action on the social determinants of health. Lancet 2008;372:1661-9.
4 Cutler DM, Lleras-Muney A. Understanding differences in health behaviors by education. J Health Econ 2010;29:1-28.

5 van Doorslaer $\mathrm{E}$, Koolman $\mathrm{X}$, Jones AM. Explaining income-related inequalities in doctor utilisation in Europe. Health Econ 2004;13:629-47.

6 Meier H, Frey M, Waeber P. Strategische Grundlagen zum Abbau gesundheitlicher Ungleichheit in der Schweiz. Schlussbericht zuhanden des Bundesamtes für Gesundheit BAG. Basel: BSS Consultants, 2011.

7 Salomon JA, Wang H, Freeman MK, et al. Healthy life expectancy for 187 countries, 1990-2010: a systematic analysis for the Global Burden Disease Study 2010. Lancet 2012;380:2144-62.

8 Singh GK, Siahpush M. Widening socioeconomic inequalities in US life expectancy, 1980-2000. Int J Epidemiol 2006;35:969-79.

9 Brønnum-Hansen $\mathrm{H}$, Baadsgaard $\mathrm{M}$. Widening social inequality in life expectancy in Denmark. A register-based study on social composition and mortality trends for the Danish population. BMC Public Health 2012;12:994

10 Macintyre S, Ellaway A, Cummins S. Place effects on health: how can we conceptualise, operationalise and measure them? Soc Sci Med 1982 2002;55:125-39.

11 Diez Roux AV, Mair C. Neighborhoods and health. Ann N Y Acad Sci 2010;1186:125-45.

12 Diez Roux AV. Investigating neighborhood and area effects on health. Am J Public Health 2001;91:1783-9.

13 Cummins S, Curtis S, Diez-Roux AV, et al. Understanding and representing 'place' in health research: a relational approach. Soc Sci Med 1982 2007;65:1825-38.

14 OECD. Health at a glance 2013: OECD indicators. [S.I.], OECD Publishing, 2013. http://dx.doi.org/10.1787/health_glance-2013-en

15 Wanner P. Räumliche Unterschiede bei der Mortalität in der Schweiz seit 1970. Neuchâtel, Bundesamt für Statistik, 2012.

16 Halonen JI, Vahtera J, Oksanen T, et al. Socioeconomic characteristics of residential areas and risk of death: is variation in spatial units for analysis a source of heterogeneity in observed associations? BMJ Open 2013;3. doi:10.1136/ bmjopen-2012-002474

17 Oliver LN, Hayes MV. Does choice of spatial unit matter for estimating small-area disparities in health and place effects in the Vancouver Census Metropolitan Area? Can J Public Health Rev Can Santé Publique 2007;98(Suppl 1):S27-34.

18 Panczak R, Galobardes B, Voorpostel M, et al. A Swiss neighbourhood index of socioeconomic position: development and association with mortality. J Epidemiol Community Health 2012;66:1129-36.

19 Bopp M, Spoerri A, Zwahlen M, et al. Cohort profile: the Swiss National Cohort-a longitudinal study of 6.8 million people. Int J Epidemiol 2009;38:379-84.

20 Fellegi IP, Sunter AB. A theory of record linkage. J Am Stat Assoc 1969;64:1183-210.

21 Fair M. Generalized record linkage system-Statistics Canada's record linkage software. Austrian J Stat 2004;33:37-53.

22 Renaud A. Methodology report-Coverage Estimation for the Swiss Population Census 2000. Neuchâtel, Bundesamt für Statistik, 2004.

23 Jonker MF, van Lenthe FJ, Donkers $B$, et al. The impact of nursing homes on small-area life expectancies. Health Place 2013;19:25-32.

24 Panczak R, Galobardes B, Spoerri A, et al. High life in the sky? Mortality by floor of residence in Switzerland. Eur J Epidemiol 2013;28:453-62.

25 Arellano-Valle RB, Azzalini R. On the unification of families of skew-normal distributions. Scand J Stat 2006;33:561-74.

26 Harrell FE. Regression modeling strategies-with applications to linear models, logistic regression, and New York, Springer, 2001. http://www.springer.com/ statistics/statistical+theory+and+methods/book/978-0-387-95232-1 (accessed 21 Apr 2014).

27 Schmidlin K, Clough-Gorr KM, Spoerri A, et al. Swiss National Cohort. Impact of unlinked deaths and coding changes on mortality trends in the Swiss National Cohort. BMC Med Inform Decis Mak 2013;13:1.

28 Pampalon R, Hamel D, De Koninck M, et al. Perception of place and health: differences between neighbourhoods in the Québec city region. Soc Sci Med 1982 2007;65:95-111

29 Stafford M, De Silva M, Stansfeld S, et al. Neighbourhood social capital and common mental disorder: testing the link in a general population sample. Health Place 2008; 14:394-405.

30 Schwartz $S$. The fallacy of the ecological fallacy: the potential misuse of a concept and the consequences. Am J Public Health 1994;84:819-24.

31 Reidpath DD, Allotey P. Infant mortality rate as an indicator of population health. J Epidemiol Community Health 2003;57:344-6.

32 Woods LM, Rachet B, Riga M, et al. Geographical variation in life expectancy at birth in England and Wales is largely explained by deprivation. J Epidemiol Community Health 2005:59:115-20.

33 Beelen R, Raaschou-Nielsen 0, Stafoggia M, et al. Effects of long-term exposure to air pollution on natural-cause mortality: an analysis of 22 European cohorts within the multicentre ESCAPE project. Lancet 2014;383:785-95.

34 Faeh D, Gutzwiller F, Bopp M; Swiss National Cohort Study Group. Lower mortality from coronary heart disease and stroke at higher altitudes in Switzerland. Circulation 2009;120:495-501. 
35 Huss A, Spoerri A, Egger M, et al.; Swiss National Cohort Study Group. Aircraft noise, air pollution, and mortality from myocardial infarction. Epidemiol Camb Mass 2010:21:829-36.

36 Kaplan R. The nature of the view from home psychological benefits. Environ Behav 2001;33:507-42.

37 Ulrich RS. View through a window may influence recovery from surgery. Science 1984;224:420-1.

38 Villeneuve PJ, Jerrett M, Su JG, et al. A cohort study relating urban green space with mortality in Ontario, Canada. Environ Res 2012;115:51-8.

39 Hajat A, Diez-Roux AV, Adar SD, et al. Air pollution and individual and neighborhood socioeconomic status: evidence from the Multi-Ethnic Study of Atherosclerosis (MESA). Environ Health Perspect 2013;121:1325-33.

40 Goodman A, Wilkinson P, Stafford M, et al. Characterising socio-economic inequalities in exposure to air pollution: a comparison of socio-economic markers and scales of measurement. Health Place 2011;17:767-74.

41 Bocquier A, Cortaredona S, Boutin C, et al. Small-area analysis of social inequalities in residential exposure to road traffic noise in Marseilles, France. Eur J Public Health 2013;23:540-6.
42 Astell-Burt T, Feng X, Mavoa $\mathrm{S}$, et al. Do low-income neighbourhoods have the least green space? A cross-sectional study of Australia's most populous cities. BMC Public Health 2014;14:292.

43 Gose M, Plachta-Danielzik S, Willié B, et al. Longitudinal influences of neighbourhood built and social environment on children's weight status. Int J Environ Res Public Health 2013;10:5083-96.

44 Michael YL, Nagel CL, Gold R, et al. Does change in the neighborhood environment prevent obesity in older women? Soc Sci Med 1982 2014;102:129-37.

45 Muennig $\mathrm{P}$, Cohen AK, Palmer A, et al. The relationship between five different measures of structural social capital, medical examination outcomes, and mortality. Soc Sci Med 1982 2013;85:18-26.

46 Durkheim E, Simpson G. Suicide: a study in sociology. London; New York: Routledge, 2002.

47 Spoerri A, Zwahlen M, Bopp M, et al. Swiss National Cohort Study. Religion and assisted and non-assisted suicide in Switzerland: National Cohort Study. Int J Epidemiol 2010;39:1486-94.

48 Busato A, Matter P, Künzi B, et al. Geographic variation in the cost of ambulatory care in Switzerland. J Health Serv Res Policy 2012;17:18-23. 